Article

\title{
Benefits of Telemonitoring of Pulmonary Function-3-Month Follow-Up of Home Electronic Spirometry in Patients with Duchenne Muscular Dystrophy
}

\author{
Eliza Wasilewska ${ }^{1, *(\mathbb{D})}$, Agnieszka Sobierajska-Rek ${ }^{2}\left(\mathbb{D}\right.$, Sylwia Małgorzewicz $^{3}$, Mateusz Soliński ${ }^{4}(\mathbb{D}$ \\ and Ewa Jassem ${ }^{1}$
}

1 Department of Allergology and Pulmonology, Medical University of Gdańsk, 80-211 Gdańsk, Poland; ejassem@gumed.edu.pl

2 Department of Rehabilitation Medicine, Medical University of Gdańsk, 80-211 Gdańsk, Poland; sobierajska@gumed.edu.pl

3 Department of Clinical Nutrition, Medical University of Gdańsk, 80-211 Gdańsk, Poland; sylwiam@gumed.edu.pl

4 Faculty of Physics, Warsaw University of Technology, 00-661 Warsaw, Poland; mateusz.solinski.dokt@pw.edu.pl

* Correspondence: ewasilewska@gumed.edu.pl; Tel./Fax: +48-58-349-3550

Citation: Wasilewska, E.;

Sobierajska-Rek, A.; Małgorzewicz,

S.; Soliński, M.; Jassem, E. Benefits of Telemonitoring of Pulmonary Function-3-Month Follow-Up of Home Electronic Spirometry in Patients with Duchenne Muscular Dystrophy. J. Clin. Med. 2022, 11, 856. https://doi.org/10.3390/ jcm11030856

Academic Editor: Miguel Castelo-Branco Sousa

Received: 15 December 2021

Accepted: 2 February 2022

Published: 6 February 2022

Publisher's Note: MDPI stays neutral with regard to jurisdictional claims in published maps and institutional affiliations.

Copyright: () 2022 by the authors. Licensee MDPI, Basel, Switzerland. This article is an open access article distributed under the terms and conditions of the Creative Commons Attribution (CC BY) license (https:// creativecommons.org/licenses/by/ $4.0 /)$.

\begin{abstract}
Background: In patients with Duchenne Muscular Dystrophy (DMD), the respiratory system determines the quality and length of life; therefore, the search for easy and safe everyday monitoring of the pulmonary function is currently extremely important, particularly in the COVID-19 pandemic. The aim of the study was to evaluate the influence of a three-month home electronic spirometry (e-spirometry) monitoring of the pulmonary function and strength of respiratory muscles as well as the patients' benefits from this telemetric program. Methods: Twenty-one boys with DMD (aged 7-22; non-ambulatory-11) received a remote electronic spirometer for home use with a special application dedicated for patients and connected with a doctor platform. Control of the hospital spirometry (forced vital capacity-FVC, forced expiratory volume in 1 second-FEV1, peak expiratory flow-PEF) and respiratory muscle strength (maximal inspiratory-MIP and expiratory pressures-MEP) before and after the three-month monitoring were performed as well telemonitoring benefit survey. Results: A total of 1403 measurements were performed; 15 of the participants were able to achieve correct attempts. There were no differences between the hospital and the home spirometry results as well as between respiratory muscle strength during v1 vs. v2 visits for the whole study group (all parameters $p>0.05$ ); the six participants achieved increased value of FVC during the study period. There was a positive correlation between $\triangle \mathrm{FVC}$ and the number of assessments during the home spirometry $(\mathrm{r}=0.7, p<0.001)$. Differences between FVC and $\mathrm{MIP}_{\mathrm{cmH} 2 \mathrm{O}}(\mathrm{r}=0.58 ; p=0.01), \mathrm{MEP}_{\mathrm{cmH}} \mathrm{O}$ $(\mathrm{r}=0.75 ; p<0.001)$ was revealed. The mean general satisfaction rating of the telemonitoring was 4.46/5 (SD 0.66) after one month and 4.91/5 (SD 0.28) after three months. The most reported benefit of the home monitoring was the improvement in breathing (38\% of participants after one month, $52 \%$ after three months of telemonitoring). Forgetting about the procedures was the most common reason for irregular measurements; the participants reported also increased motivation but less time to perform tests. Conclusions: The study indicates high compliance of the home telemonitoring results with the examination in the hospital. Benefits from home spirometry were visible for all participants; the most important benefit was breathing improvement. The remote home spirometry is usable for everyday monitoring of the pulmonary function in DMD patients as well can be also treated as respiratory muscle training.
\end{abstract}

Keywords: telemonitoring; digital health; home monitoring; e-monitoring of pulmonary function; home monitoring pulmonary function; rare diseases; Duchenne muscular dystrophy; pulmonary function test; spirometry; AioCare; COVID-19; adherence 


\section{Introduction}

Duchenne Muscular Dystrophy (DMD) is the most common and progressive muscular dystrophy in childhood. Respiratory system and heart functioning determine the patient's life expectancy, which, thanks to multi-specialized coordinated care, has now increased from a dozen to around 30 years [1].

Respiratory muscle weakness seems to be a major component of respiratory dysfunction [2]. It can be observed that the consequence of these changes is the reduction of the vital capacity of the lungs. It is known that pulmonary function declines at a rate of $6-11 \%$ annually in patients with DMD [3-5]. Moreover, respiratory muscle weakness leads to secondary changes such as decreased lung compliance, ineffective cough with deterioration of airway clearance, and repeated infections [6,7].

The time of the SARS-Cov-2 virus pandemic caused a search for new solutions in the field of diagnosis, monitoring, and contact with the patient and the acceleration of their implementation. The methods of telemonitoring of the patients' condition at home are known and available in some specialties, e.g., cardiology, endocrinology, psychiatry, and geriatrics [8-12]. Automatic transmission of physiologic data (weight, blood pressure, heart rate and rhythm) using networked devices through mobile phones, the transmission of data acquired from wearable monitoring technology (heart, respiratory rate and temperature), or implanted therapeutic devices (pacemakers, defibrillators) are widely used in cardiology care $[13,14]$. Remote monitoring devices transmitting blood glucose levels, blood pressure, heart rate and weight are useful in everyday practices in patients with diabetes mellitus $[15,16]$. There are some reports of telemonitoring in pulmonology patients with asthma, cystic fibrosis, and after lung transplants; however, there are still no appropriate telemetric methods for monitoring lung function in patients with neuromuscular disorders $[17,18]$.

In patients with DMD, the respiratory system determines the quality and length of life; therefore, the search for easy and safe monitoring of the pulmonary function is currently extremely important, particularly in the COVID-19 pandemic, when personal contact of the patient with the physician is limited $[19,20]$. Clinicians need to know the patient's clinical condition, especially in the case of chronic disease. Moreover, methods of improving the functioning of the muscles of the respiratory system are also limited. Steroid therapy (prednisone or deflazacort) is a confirmed factor that delays the deterioration of lung function but does not cause its' improvement [21]. In turn, the DELOS study, (Duchenne muscular dystrophy long-term idebenone study) showed that idebenone, a short-chain benzoquinone, significantly reduced the loss of pulmonary function over the 52-week study period in a DMD patient cohort not using a concomitant corticosteroid therapy. Currently, this treatment is only available in clinical trials [22-24]. Respiratory training is recommended as one of the key elements for DMD patients and is another method of improving pulmonary function [25-28]. Currently, during the COVID-19 pandemic, preference is given to the telerehabilitation of respiratory muscles. However, it was found that some patients had difficulties with telerehabilitation such as remembering to do the exercises at all or problems with the regularity of training at home [29]. It became necessary to find a solution for the problem of monitoring the respiratory system during exercises and reminding patients about performing the exercises.

That is why we implemented a program for remote everyday monitoring of pulmonary function in DMD patients. In our previous study, we showed that it was possible to measure and monitor lung function at home by the patients themselves [30]. Currently, we wanted to evaluate what is the effect of using this method for the next three months on lung function in these patients.

The aim of the study was to evaluate the influence of the three-month home espirometry monitoring on the pulmonary function and strength of respiratory muscles as well as the patients' benefits from this telemetric program. 


\section{Materials and Methods}

\subsection{Study Design}

This prospective, control-case, open-label study was conducted from June 2021 to October 2021 as the third part of the project: "E-monitoring of the pulmonary function in patients with Duchenne muscular dystrophy undergoing respiratory rehabilitation at home"; details of the other parts were described elsewhere [30].

The patients with DMD were recruited from Rare Disease Centre, Medical University of Gdańsk, University Clinical Centre; Poland which is a member of the TREAT NMD Alliance Neuromuscular Network. Approval for the study was obtained from The Local Committee of Ethics no. NKBBN/260/2021, which conformed to the principles embodied in the Declaration of Helsinki. Written informed consent was obtained from the participants and parents of each patient.

\subsection{Participants}

The study population included boys with DMD diagnosis based on the guidelines [1]. Inclusion criteria were as follows: (1) Male, $\geq 7$ years and $<25$ years of age; (2) ability to perform spirometry and respiratory muscle strength test; (3) stated willingness to comply with all study procedures (AioCare device used) and availability for the duration of the study; and (4) no COVID-19 infection.

Due to the number of telemonitoring devices, 30 boys who met the criteria were invited to participate in the project. The duration of the study was 12 weeks, during which the participants made 3 visits at hospital.

V1 visit (enrolment): The physical examination, anthropometry measurement, Vignos scale (VS), Brooke scale (BS), handgrip strength and respiratory system assessment: spirometry (Jaeger, Hoechberg, Germany), and respiratory muscle strength test (MicropPRM, Rochester, Kent, UK) were performed in all enrolled patients. Each patient received a device for telemonitoring: electronic individual spirometer (AioCare) for daily spirometry measurements at home.

V2 visit (control): After 4 weeks of telemonitoring, patients came to evaluate the correctness of the e-spirometry measurements. They also filled in a questionnaire: Telemonitoring benefits survey (survey 1 ).

V3 visit (follow up): At the follow-up after 12 weeks, hospital spirometry, respiratory muscle strength tests were conducted and the Telemonitoring benefits survey (survey 2) was filed in by participants again.

\subsection{Respiratory System Assessment}

\subsubsection{Spirometry (Telemonitoring and Hospital Spirometry Control)}

Telemonitoring of pulmonary function was performed by AioCare system, which consists of the device for home spirometry (AioCare ${ }^{\circledR}$ spirometers, Healthup, Warsaw, Poland), AioCare ${ }^{\circledR}$ Patient application, and AioCare ${ }^{\circledR}$ Doctor platform [31]. AioCare espirometer is a small, convenient device and can be used anywhere; even by children over 5 years of age. The participants were asked to perform on their own three correct spirometry measurements twice daily, morning and evening at home during a 12-week period. They performed measurements themselves with the help of caregivers after a previous 4-week training period of using AioCare device at home, which was described in another publication [30].

The hospital control spirometry (Pneumo Screen, Jaeger, Hoechberg, Germany spirometer) the participants performed twice (during the V1 and V3 visit) by the same pediatric pulmonologist who evaluated these results. A minimum of 3 and up to 5 manoeuvres with a maximum effort were attempted by each participant.

All measurements of the hospital and the home spirometry were performed according to the European Respiratory Society and American Thoracic Society recommendations $[32,33]$. The highest value of forced vital capacity (FVC), forced expiratory volume 
in $1 \mathrm{~s}$ (FEV1), peak expiratory flow (PEF) expressed as litres (L), litres per minute (L/min) accordingly, and percent predicted value from correct acceptable attempts were evaluated.

The results of hospital spirometry were submitted to the ePULMoDMD database. The test results of the home e-spirometry were sent from the AioCare spirometer via the AioCare application for iOS or Android (used by participants' smartphones) to the AIOCARE Doctor on-line panel and were available to the practitioner in real time. Finally, all test results of the home e-spirometry were also collected in the ePULMoDMD Database. The results were compared with results from the hospital spirometry.

\subsubsection{Respiratory Muscle Assessment}

Respiratory muscle strength was assessed by measuring the maximal inspiratory pressure (MIP), and the maximal expiratory pressure (MEP) using a mouth pressure meter (MicroRPM; Micro Medical Ltd., Rochester, England). Operators were specially trained to do MIP and MEP. The manoeuvre made by the subject was a maximal inspiration or expiration sustained for at least one second against a blocked airway. The highest positive MEP value and the lowest negative MIP value in three or more attempts were chosen and calculated percent predicted MEP (MEP\%) and MIP (MIP\%) values according to the formulas: MEP $\times 100 /(7.619+(7.806 \times$ age $)+(0.004 \times$ height $\times$ weight $)$ and - MIP $\times$ $100 /(-27.020-(4.132 \times$ age $)-(0.003 \times$ height $\times$ weight $)[34]$.

\subsubsection{Functional Status and Hand Grip Strength}

The severity of the disease was evaluated by ambulatory status (yes/no) and the Vignos scale (VS). The vs. allows staging of the disease and focuses on functional ambulatory activities. The scores on the vs. range from 1 to 10 (1-the subject can walk and climb stairs without assistance, 10-the subject is confined to a bed) [35].

Upper limb functional status was assessed with the 6-point Brooke scale (BS) (1-the subject can abduct their arms in a full circle until they touch above their head, 6-the subject has no useful function of the hands) [36].

Maximal grip strength was measured using dynamometer FT-5988-N1 (Spais, Gdansk, Poland). Trials were carried out with strong verbal encouragement, asking the patients to provide maximal voluntary isometric contractions for $3 \mathrm{~s}$. The remaining period of about $30 \mathrm{~s}$ was respected between the trials. Patients were asked to perform three trials. The mean value was calculated from three valid trials [37].

\subsection{Telemonitoring Benefits Survey}

Details of satisfaction of patients and benefits from using the home telemonitoring of pulmonary function were collected from a survey after 1 month (survey 1 ) and after 3 months (survey 2) of using the home spirometry. The patients were asked to express their general satisfaction from the AioCare home spirometry on the 5-point scale, where "1" meant the worst and " 5 " meant the best score. The other questions concerned benefits and problems with regular measurements from the home spirometry.

\subsection{Statistical Analysis}

The results of the statistical analysis were expressed as mean (standard deviation) or median (interquartile range). The comparison of the mean values of the spirometry parameters between the averaged home spirometry results (from 3 months of monitoring) and ambulatory spirometry was performed using paired, parametric Student $t$-test, or nonparametric Wilcoxon signed-rank test (depending on whether the compared values were normally distributed, which was evaluated using the Shapiro-Wilk test) with a significance level of $p=0.05$. Pearson correlation coefficients between spirometry parameters obtained during either the home and the laboratory spirometry and other clinical indices were calculated. The relationship between the changes of $\mathrm{FVC}$ (and $\mathrm{FVC} \%$ ) parameter during the home monitoring as well as between ambulatory visits and other clinical data (age, BMI, handgrip strength, MIP, MEP, ambulatory status, and number of spirometry measurements) 
was analyzed using backward stepwise linear regression models. Changes of the spirometry parameters values $(\Delta)$ over 90 days were calculated using linear regression for each patient; the $\Delta$ value was defined as the difference of the estimated value of the parameter from the linear regression model between the 90th and the 1st day of monitoring.

\section{Results}

\subsection{Participants}

Finally, 21 out of 30 participants were notified of the v1 visit and received an e-home spirometer. The characteristic of the study group is presented in Table 1.

Table 1. Anthropometry and clinical characteristics of the study group.

\begin{tabular}{|c|c|}
\hline & $\begin{array}{c}\text { DMD Participants } \\
\qquad n=21\end{array}$ \\
\hline Age years & $12.8(4.4)$ \\
\hline Weight kg & $51.3(18.2)$ \\
\hline Height $\mathrm{cm}$ & $148(16)$ \\
\hline $\mathrm{BMI} \mathrm{kg} / \mathrm{m}^{2}$ & $22.7(5.3)$ \\
\hline Brooke scale & 2 (4) Median (Q3-Q1) \\
\hline Vignos scale & 8 (7.5) Median (Q3-Q1) \\
\hline Hand grip strength & $66.3(31.12)$ \\
\hline Ambulatory yes/no & $10 / 11$ \\
\hline Mutation & $\begin{array}{c}\text { Deletions } 68.4 \% \\
\text { Point mutations } 15.8 \% \\
\text { Duplications } 10.5 \% \\
\text { Lack of mutation } 5.3 \%\end{array}$ \\
\hline
\end{tabular}

\subsection{Pulmonary Function Test}

\subsubsection{Telemonitoring Compliance}

Using home e-spirometry, the participants performed a total of 1403 measurements (mean 66.8 (SD 49.8) over 90 days of study time. Fifteen patients were able to perform correct attempts according to ATS/ERS 2019 criteria [33]. Sessions with at least one correct measurement presented $85.5 \%$ of the participants. At least 30 days with one performed assessment per day presented thirteen participants and with at least two assessments per day-six patients (Table 2). Since two participants took less than 10 measurements during the study period, they were excluded from further calculations (ID3 patient, ID15 patient).

Table 2. Compliance with home e-spirometry for individual participants.

\begin{tabular}{cccccc}
\hline & & \multicolumn{2}{c}{ Correctness } & \multicolumn{2}{c}{ Adherence } \\
\cline { 2 - 6 } Participants ID & $\begin{array}{c}\text { Number of } \\
\text { Examinations }\end{array}$ & $\begin{array}{c}\text { Correct } \\
\text { Examinations } \\
\text { (ATS/ERS 2019) } \\
\text { nb (\%) }\end{array}$ & $\begin{array}{c}\text { Examinations } \\
\text { with 1 Correct } \\
\text { Maneuver } \\
\text { nb (\%) }\end{array}$ & $\begin{array}{c}\text { Days with 2 } \\
\text { Examinations } \\
\text { nb (\%) }\end{array}$ & $\begin{array}{c}\text { Days with 1 } \\
\text { Examination } \\
\text { nb (\%) }\end{array}$ \\
\hline 1 & 60 & $50(83.3 \%)$ & $58(96.7 \%)$ & $3(3.3 \%)$ & $57(63.3 \%)$ \\
\hline 2 & 176 & $0(0 \%)$ & $47(26.7 \%)$ & $85(94.4 \%)$ & $89(98.9 \%)$ \\
\hline 3 & 3 & $0(0 \%)$ & $1(0 \%)$ & $0(0 \%)$ & $2(2.22 \%)$ \\
\hline 4 & 133 & $61(45.9 \%)$ & $114(85.7 \%)$ & $44(48.9 \%)$ & $82(91.1 \%)$ \\
\hline 5 & 86 & $10(11.6 \%)$ & $65(75.6 \%)$ & $21(23.3 \%)$ & $64(71.1 \%)$ \\
\hline 7 & 170 & $0(0 \%)$ & $165(97.1 \%)$ & $76(84.4 \%)$ & $90(100 \%)$ \\
\hline 8 & 68 & $0(0 \%)$ & $39(57.4 \%)$ & $12(13.3 \%)$ & $55(61.1 \%)$ \\
\hline 9 & 88 & $81(92 \%)$ & $88(100 \%)$ & $1(1.1 \%)$ & $87(96.7 \%)$ \\
\hline
\end{tabular}


Table 2. Cont.

\begin{tabular}{cccccc}
\hline & & \multicolumn{2}{c}{ Correctness } & \multicolumn{2}{c}{ Adherence } \\
\cline { 2 - 6 } Participants ID & $\begin{array}{c}\text { Number of } \\
\text { Examinations }\end{array}$ & $\begin{array}{c}\text { Correct } \\
\text { Examinations } \\
\text { ATS/ERS 2019) } \\
\text { nb (\%) }\end{array}$ & $\begin{array}{c}\text { Examinations } \\
\text { with 1 Correct } \\
\text { Maneuver } \\
\text { nb (\%) }\end{array}$ & $\begin{array}{c}\text { Days with 2 } \\
\text { Examinations } \\
\text { nb (\%) }\end{array}$ & $\begin{array}{c}\text { Days with 1 } \\
\text { Examination } \\
\text { nb (\%) }\end{array}$ \\
\hline 10 & 14 & $3(21.4 \%)$ & $11(78.6 \%)$ & $3(3.3 \%)$ & $10(11.1 \%)$ \\
\hline 11 & 12 & $0(0 \%)$ & $11(91.7 \%)$ & $3(3.3 \%)$ & $9(10 \%)$ \\
\hline 12 & 22 & $5(22.7 \%)$ & $20(90.9 \%)$ & $1(1.1 \%)$ & $21(23.3 \%)$ \\
\hline 13 & 65 & $6(9.2 \%)$ & $57(87.7 \%)$ & $12(13.3 \%)$ & $50(55.6 \%)$ \\
\hline 14 & 42 & $10(23.8 \%)$ & $27(64.3 \%)$ & $8(8.9 \%)$ & $34(37.8 \%)$ \\
\hline 15 & 1 & $0(0 \%)$ & $1(100 \%)$ & $0(0 \%)$ & $1(1.1 \%)$ \\
\hline 16 & 90 & $37(41.1 \%)$ & $89(98.9 \%)$ & $24(26.7 \%)$ & $66(73.3 \%)$ \\
\hline 17 & 106 & $96(90.6 \%)$ & $105(99.1 \%)$ & $34(37.8 \%)$ & $69(76.7 \%)$ \\
\hline 19 & 103 & $49(47.6 \%)$ & $84(80.6 \%)$ & $31(34.4 \%)$ & $71(78.9 \%)$ \\
\hline 20 & 26 & $16(61.5 \%)$ & $26(100 \%)$ & $1(1.6 \%)$ & $25(41 \%)$ \\
\hline 21 & 23 & $0(0 \%)$ & $21(91.3 \%)$ & $7(21.2 \%)$ & $13(39.4 \%)$ \\
\hline Total nb & 97 & $21(21.6 \%)$ & $78(80.4 \%)$ & $39(45.9 \%)$ & $46(54.1 \%)$ \\
\hline Mean \pm SD & 1403 & 450 & 1125 & 410 & 954 \\
\hline
\end{tabular}

$\mathrm{nb}$, number.

In the final study group $(n=19)$ the correctness of spirometry increased, although the difference between 1 and $2+3$ months was not statistically significant both for examinations meeting ATS/ERS 2019 criteria ( $25.4 \%$ vs. $37.8 \%, p=0.130$ ) and for examinations with at least one correct manoeuvre $(81.6 \%$ vs. $88.2 \%, p=0.173)$ —see Figure $1 \mathrm{~A}, \mathrm{~B}$.

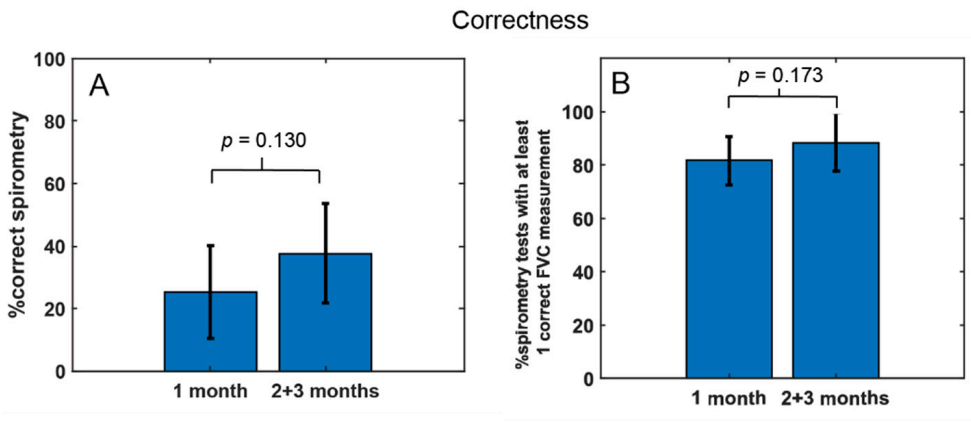

Adherence
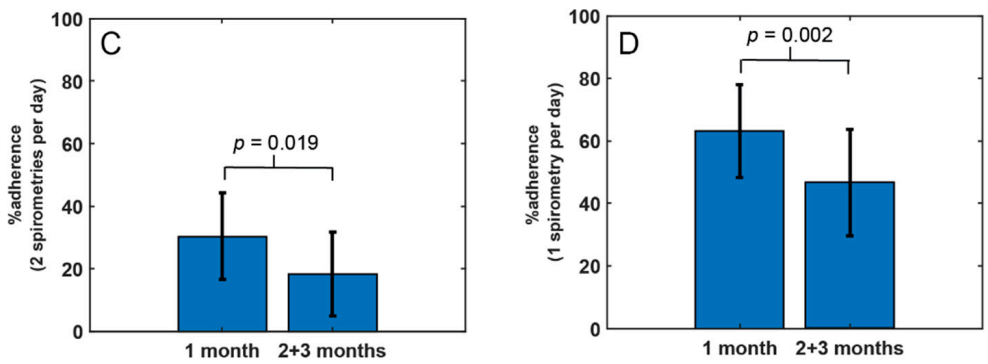

Figure 1. Compliance analysis of pulmonary function telemonitoring. Correctness: (A) percentage of the correct examinations (ATS/ERS 2019) [31]; (B) percentage of the exams with at least one corrected measurement. Adherence: $(C)$ percentage of the days with at least two examinations/total number of the days ((30 or 60 days) $\times 100 \%)$; (D) percentage of the days with at least one measurement/total number of the days ((30 or 60 days $) \times 100 \%)$. 
The compliance analysis showed that the mean adherence decreased significantly in two and three months in comparison to the first month $(30.1 \%$ vs. $18.3 \% ; p=0.019$ for days with two examinations per day) and (63.2\% vs. $46.7 \% ; p=0.0022$ for days with one examination per day)—see Figure 1C,D.

\subsubsection{Study Group Spirometry}

The mean values of the home telemonitoring and hospital spirometry are presented in Table 3. There were no differences between mean hospital vs. home parameters of spirometry (FVC, FEV1, PEF) (for all parameters $p>0.05$ ). There were also no differences in mean parameters of the hospital spirometry between the first and third visits as well as between day one and day 90 in the mean value of the home e-spirometry $(\triangle \mathrm{FVC}, \triangle \mathrm{FEV} 1$, $\triangle \mathrm{PEF}$ ) (for all parameters $p>0.05)$; (Table 3).

Table 3. Mean values of hospital and home spirometry for study group (Mean $\pm \mathrm{SD}$ ).

\begin{tabular}{|c|c|c|c|c|c|c|}
\hline & \multicolumn{6}{|c|}{$\begin{array}{l}\text { DMD Participants } \\
\qquad n=19\end{array}$} \\
\hline & \multicolumn{2}{|c|}{ Hospital } & \multirow{2}{*}{$p$-Value } & \multirow{2}{*}{$\begin{array}{l}\text { Home } \\
\text { Mean }\end{array}$} & \multicolumn{2}{|c|}{$p$-Value } \\
\hline & Visit 1 & Visit 3 & & & V1 vs. Home & V3 vs. Home \\
\hline FVC (L) & $2.02(0.57)$ & $2.24(0.55)$ & 0.211 & $2.08(0.66)$ & 0.505 & 0.332 \\
\hline FVC (\%pv) & $74.0(22.2)$ & 80.1 (18.7) & 0.307 & $74.2(26.0)$ & 0.918 & 0.905 \\
\hline FEV1/FVC & $87.8(7.6)$ & $88.5(6.2)$ & 0.690 & $83.0(18.3)$ & 0.224 & 0.435 \\
\hline FEV1 (L) & $1.82(0.56)$ & $2.00(0.48)$ & 0.765 & $1.72(0.71)$ & 0.339 & 0.488 \\
\hline FEV1 (\%pv) & $77.6(24.4)$ & $85.8(20.0)$ & 0.141 & $71.3(33.0)$ & 0.170 & 0.230 \\
\hline $\mathrm{PEF}(\mathrm{L} / \mathrm{min})$ & $209(56)$ & $228(55)$ & 0.653 & $193(80)$ & 0.236 & 0.323 \\
\hline PEF (\%pv) & $69.0(23.0)$ & $74.2(19.6)$ & 0.606 & $64.26(27.88)$ & 0.322 & 0.371 \\
\hline
\end{tabular}

forced vital capacity, FVC; forced expiratory volume in $1 \mathrm{~s}$, FEV1; peak expiratory flow, PEF; pv, predicted value.

\subsubsection{Individual Spirometry}

For each individual participant, the value of FVC measurement during the hospital and the home spirometry is presented in Table 4. Change in the home e-spirometry parameter values ( $\triangle \mathrm{FVC} \mathrm{L}$ and $\triangle \mathrm{FVC} \% \mathrm{pv}$ ) over 90 days was calculated using linear regression for each parameter. After fitting a straight line, the difference at $\mathrm{d}=90$ days (or the last day of monitoring) and day $=0$ was calculated. Results of $\triangle F V C$ revealed increasing trends in the six selected patients (see Table 4 and Figure 2). Visualizations for other individual parameters of spirometry (FEV1, PEF) are presented in Supplement Materials. This subgroup performed over 65 measurements per patient during the study period and at least $50 \%$ of manoeuvres were correct. There was a positive correlation between $\triangle \mathrm{FVC}$ (L) and the number of assessments through home spirometry $(\mathrm{r}=0.7, p<0.001)$; however, no relationship was revealed with other telemonitoring compliance (number of correct examinations of the home spirometry and adherence) for all participants (for all parameters $p>0.05)$.

Table 4. Differences of forced vital capacity (FVC) values between two control points (start and 90 days follow-up) in hospital spirometry and home spirometry for individual participants.

\begin{tabular}{ccccc}
\hline \multirow{2}{*}{ Participants ID } & \multicolumn{4}{c}{ Spirometry } \\
\cline { 2 - 5 } & \multicolumn{2}{c}{ Hospital } & \multicolumn{2}{c}{ Home } \\
\cline { 2 - 5 } & 0.12 & 5.4 & $-0.08^{*}$ & $-3.09^{*}$ \\
\hline 1 & -0.14 & -13.8 & $-0.51^{*}$ & $-30.36^{*}$ \\
\hline 2 & - & - & - & - \\
\hline 3 ex & & & & \\
\hline
\end{tabular}


Table 4. Cont.

\begin{tabular}{|c|c|c|c|c|}
\hline \multirow{3}{*}{ Participants ID } & \multicolumn{4}{|c|}{ Spirometry } \\
\hline & \multicolumn{2}{|c|}{ Hospital } & \multicolumn{2}{|c|}{ Home } \\
\hline & $\Delta F V C$ (Liter) & $\Delta F V C(\% p v)$ & $\Delta F V C$ (Liter) & $\Delta F V C(\% p v)$ \\
\hline 4 & -0.04 & 4.3 & 0.31 & 10.36 \\
\hline 5 & 0.24 & 7.7 & -0.02 & -0.55 \\
\hline 6 & -0.01 & -0.8 & $0.25 *$ & $8.82 *$ \\
\hline 7 & 0.4 & 16.2 & $0.25 *$ & $9.82 *$ \\
\hline 8 & 0.13 & 5.2 & 0.02 & 0.71 \\
\hline 9 & -0.0 & $0.0-$ & -0.21 & -10.43 \\
\hline 10 & -0.12 & -2.9 & -0.65 & -15.28 \\
\hline 11 & -0.14 & -5.5 & -0.21 & -9.3 \\
\hline 12 & -0.02 & -1.1 & 0.01 & 0.4 \\
\hline 13 & -0.18 & -4.4 & 0.06 & 2.78 \\
\hline 14 & 0.07 & 2 & -0.03 & -0.91 \\
\hline $15 \mathrm{ex}$ & - & - & - & - \\
\hline 16 & 0.25 & -2.7 & $0.13 *$ & $4.98^{*}$ \\
\hline 17 & -0.01 & -0.5 & -0.05 & -2.55 \\
\hline 18 & 0.12 & 0.0 & $-0.11 *$ & $-3.37 *$ \\
\hline 19 & -0.0 & $0.0-$ & -0.13 & -8.47 \\
\hline 20 & -0.0 & $0.0-$ & 0.14 & 2.95 \\
\hline 21 & -0.0 & $0.0-$ & -0.2 & -3.74 \\
\hline Mean (STD) & $0.04(0.17)$ & $0.61(6.83)$ & $-0.05(0.24)$ & $-2.36(9.39)$ \\
\hline
\end{tabular}

ex, excluded participants; Differences for home spirometry were calculated as the value of FVC (L) or FVC\% after 3 months minus estimated value at 1st day taken from linear regression model fitted to the data. Symbol* means that the slope coefficient of the fitted lines is significantly different from zero $(p$-value $<0.05)$.

\subsubsection{Respiratory Muscle Assessment}

The value of maximal expiratory and inspiratory pressure are given in Table 5 . There were no differences between the first and third visits for mean parameters of MIP $(\triangle \mathrm{MIP}$; $p=0.169)$, and MEP $(\triangle \mathrm{MEP} ; p=0.533)$. There was also no correlation between MIP and MEP parameters and age $(p>0.05)$.

Table 5. Values of respiratory muscle assessment.

\begin{tabular}{cccc}
\hline & \multicolumn{2}{c}{ DMD Participants } & $\begin{array}{c}p \text {-Value } \\
\text { V1 vs. V3 }\end{array}$ \\
\cline { 2 - 3 } & Visit 1 & Visit 3 & 0.169 \\
\hline MIP $_{\mathrm{cmH2O}}$ & $39.7(21.3)$ & $49.4(20.0)$ & 0.380 \\
\hline MIP \%pv & $38.3(22.3)$ & $46.8(24.2)$ & 0.533 \\
\hline $\mathrm{MEP}_{\mathrm{cmH2O}}$ & $34.2(14.1)$ & $40.4(20.8)$ & 0.616 \\
\hline $\mathrm{MEP} \% \mathrm{pv}$ & $25.0(10.5)$ & $29.1(17.6)$ & \\
\hline
\end{tabular}

maximal inspiratory pressure, MIP; maximal expiratory pressure, MEP; predictive value, $\mathrm{pv}$. 

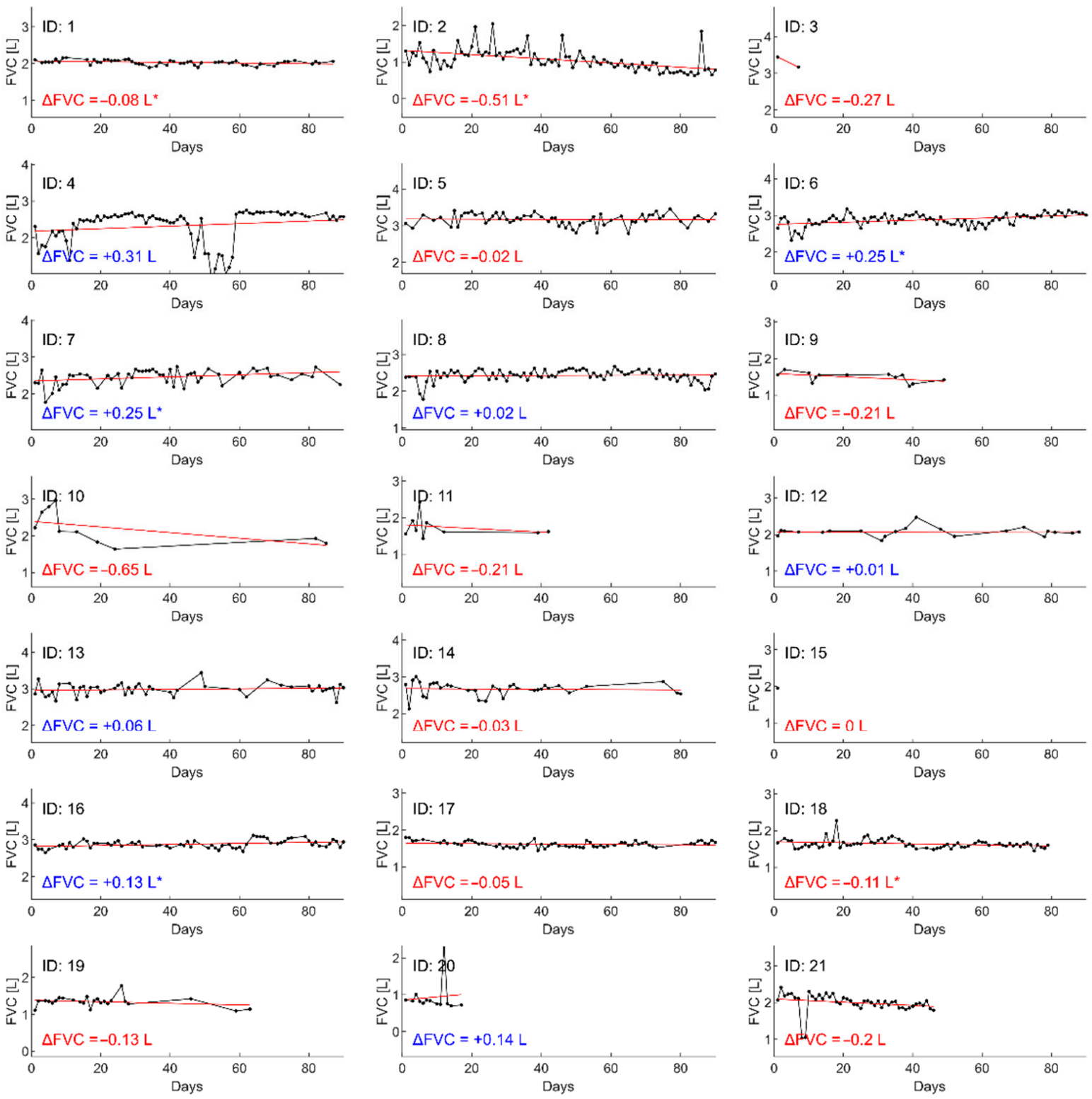

Figure 2. Daily forced vital capacity (FVC (L) charts with a matched straight line for individual participants. Change in spirometry parameter values $(\triangle \mathrm{FVC})$ over 90 days was calculated using linear regression for each parameter. After fitting a straight line, the difference at $d=90$ days (or last day of monitoring) and day $=0$ was calculated. Symbol * means that the slope coefficient of the fitted lines is significantly different from zero $(p$-value $<0.05)$.

\subsection{Relationship between FVC and Respiratory Muscles}

Basing on the analysis of the assessments from v1 visit, the correlation between FVC $(\mathrm{L})$ and $\mathrm{MIP}_{\mathrm{cmH} 2 \mathrm{O}}(\mathrm{r}=0.58 ; p=0.01)$ as well between FVC $(\mathrm{L})$ and $\mathrm{MEP}_{\mathrm{cmH} 2 \mathrm{O}}(\mathrm{r}=0.75$; $p<0.001)$ was revealed. There was also a fair correlation between $\mathrm{FVC} \%$ vs. MEP\% $(\mathrm{r}=0.46 ; p=0.05)$ and no correlation between FVC $\%$ vs. MIP\% $(\mathrm{r}=0.32 ; p=0.20)$-see Figure $3 \mathrm{~A}-\mathrm{D}$. 

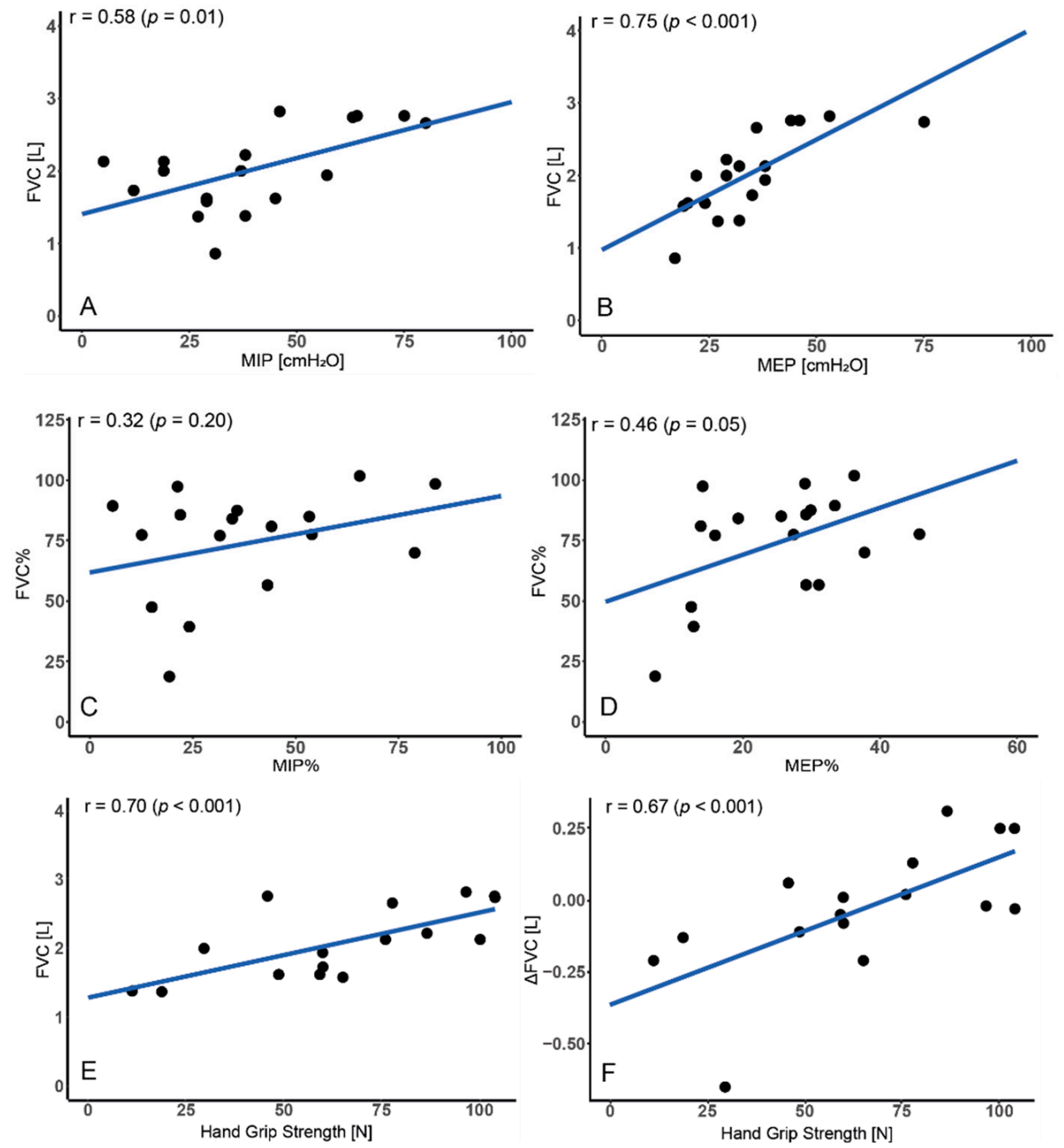

Figure 3. Relationship between forced vital capacity $(\mathrm{FVC})$ and $(\mathbf{A}, \mathbf{B})$ maximal inspiratory pressure $(\mathrm{MIP}) ;(\mathbf{C}, \mathrm{D})$ maximal expiratory pressure (MEP); (E,F) handgrip strength.

\subsection{Relationship between FVC and Motor Function}

Neither BS nor vs. was correlated with FVC or $\triangle$ FVC measured both in the home and the hospital spirometry and with telemonitoring compliance (frequency, correctness, adherence) (for all parameters $p>0.05$ ). There was correlation between handgrip strength and FVC $(\mathrm{L})(\mathrm{r}=0.70 ; p<0.001)$ as well $\triangle \mathrm{FVC}$ measured in the home e-spirometry $(\mathrm{r}=0.67$; $p<0.001)$ and the hospital spirometry $(\mathrm{r}=0.61 ; p=0.02)$ - see Figure $3 \mathrm{E}, \mathrm{F}$.

\subsection{Regression Analysis}

Step-wise linear regression analysis showed that patients with better handgrip strength presented a higher $\triangle \mathrm{FVC} \%$ in the home e-spirometry $(p=0.016)$ (model 1) and also in the hospital spirometry (model 2,3$)(p=0.002$ and $p=0.001$, respectively). Correlation coefficients between clinical variables and $\triangle \mathrm{FVC}(\mathrm{L})$ are presented in Table 6. 
Table 6. Summary of stepwise linear regression models for predicting spirometry forced vital capacity (FVC (L) or $\triangle \mathrm{FVC} \%$ ) or with the clinical, anthropometric, and spirometry data.

\begin{tabular}{|c|c|c|}
\hline \multicolumn{3}{|c|}{ Model 1 ( $\triangle$ FVC $\%$, e-Spirometry) } \\
\hline Variables & Coefficient $(95 \% \mathrm{CI})$ & $p$-value \\
\hline Intercept & $-8.599(-9.075 \sim-8.409)$ & 0.090 \\
\hline Age & $-0.542(-5.596 \sim-0.539)$ & 0.196 \\
\hline Hand Grip Strength & $0.150(0.149 \sim 0.154)$ & 0.016 \\
\hline Number of measurements & $0.062(0.063 \sim 0.071)$ & 0.078 \\
\hline \multicolumn{3}{|c|}{ Model 2 ( $\triangle \mathrm{FVC}(\mathrm{L})$, hospital spirometry) } \\
\hline Variables & Coefficient $(95 \% \mathrm{CI})$ & $p$-value \\
\hline Intercept & $0.092(-0.117 \sim 0.485)$ & 0.499 \\
\hline Hand Grip Strength & $0.007(0.011 \sim 0.018)$ & 0.002 \\
\hline MEP & $-0.005(-0.017 \sim-0.003)$ & 0.117 \\
\hline BMI & $-0.008(-0.028 \sim-0.003)$ & 0.197 \\
\hline Number of measurements & $-0.002(-0.006 \sim-0.002)$ & 0.107 \\
\hline Ambulatory & $-0.164(-0.467 \sim-0.190)$ & 0.026 \\
\hline \multicolumn{3}{|c|}{ Model 3 ( $\Delta$ FVC $\%$, hospital spirometry) } \\
\hline Intercept & $4.632(4.482 \sim 5.239)$ & 0.237 \\
\hline Age & $-0.403(-0.450 \sim-0.339)$ & 0.131 \\
\hline Hand Grip Strength & $-0.255(-0.259 \sim-0.268)$ & $<0.001$ \\
\hline MEP & $-0.152(-0.167 \sim-0.151)$ & 0.095 \\
\hline MIP & $-0.117(-0.121 \sim-0.114)$ & 0.010 \\
\hline Number of measurements & $-0.065(-0.070 \sim-0.065)$ & 0.030 \\
\hline
\end{tabular}

\subsection{Telemonitoring Benefits Survey}

The ratings of general satisfaction varied from five to three for Survey One and from five to four for Survey Two. The mean general satisfaction rating of the home spirometry was 4.46/5 (SD 0.66) in Survey One and 4.91/5 (SD 0.28) in Survey Two. There was no significant difference between general satisfaction in Surveys One and Two $(p=0.095)$. Benefits from the home spirometry were visible for $80 \%$ of respondents in Survey One and all respondents in Survey Two. Breathing improvement was indicated as the most important benefit from the telemonitoring pulmonary function for more respondents (Figure 4). The most common reason for irregular measurements was forgetting about the procedures. The patients reported increased motivation but less time to perform tests. Reasons for benefits and irregular measurements reported by the participants in Surveys One and Two are presented in Figure 4. 

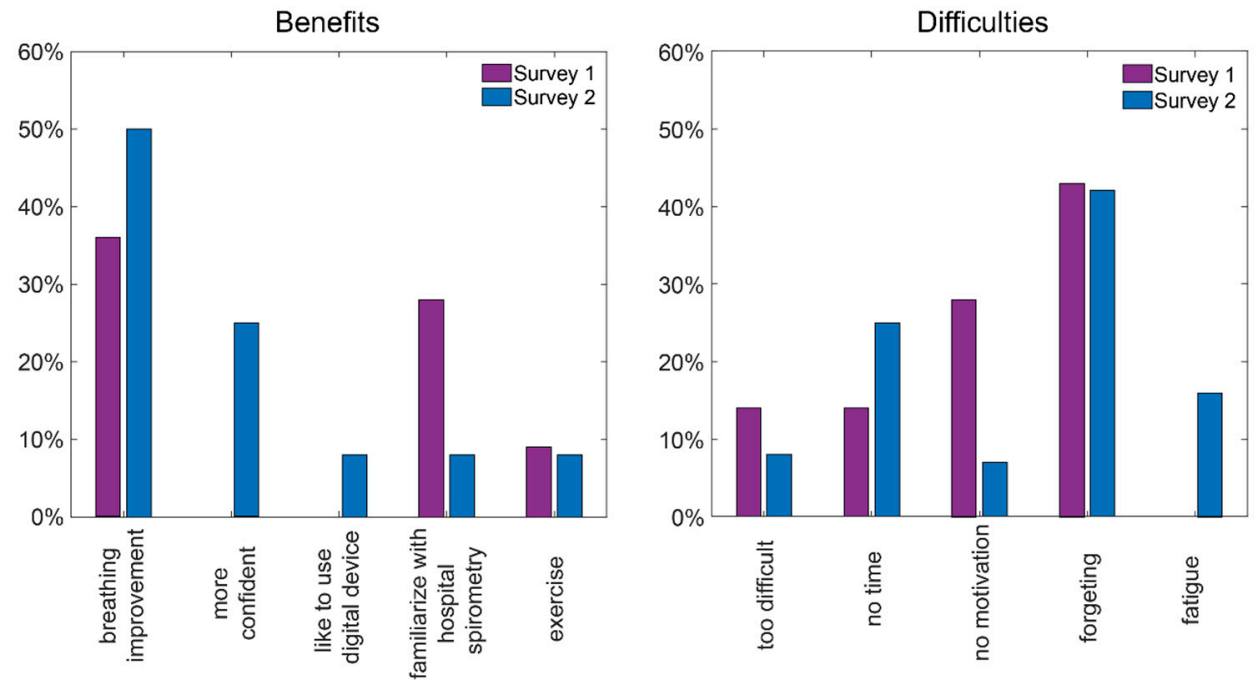

Figure 4. Benefits of telemonitoring of pulmonary function and reasons for irregular measurements reported by participants.

\section{Discussion}

The present study looked at the clinical effects of telemonitoring of lung function by daily use of a home handheld e-spirometer-networked device with automatic transmission through mobile phone results of pulmonary function tests in patients with DMD.

Our study confirmed high compliance of the home telemonitoring assessments with the examinations performed in the hospital. Moreover, the telemonitoring results showed that all patients were able to perform the tests correctly at home, although the ATS/ERS2019 correctness criteria were not reached by $20 \%$ of the patients.

It should be taken into account that the correctness criteria of spirometry published by ATS/ERS2019 are very demanding. Repeatability criteria applied acceptance to FVC require three correct manoeuvrers and the difference between the two highest FVC values is less than $150 \mathrm{~mL}$ [33]. Patients with DMD, due to muscle weakness, may have difficulties achieving all of the above-listed repeatability criteria in subsequent measurements; however, they are able to perform at least one correct measurement during a session. Despite this, spirometry is still recommended to monitor lung function in patients with DMD [2].

The results of our patients' spirometry are surprisingly good in comparison to the study by Eaton et al., where, after attending spirometry workshops, only 33\% of tests performed by trained primary care technicians met the guidelines of ATS criteria [38]. In turn, the other studies showed that lung function test results collected during the home asthma telemonitoring are comparable to those collected under the supervision of trained professionals on commercial spirometers [35,39].

Attempts to conduct telespirometry have so far been used for obstructive diseases such as asthma and chronic obstructive lung disease (COPD) around 20 years previous. The most widely it was applied in patient self-monitoring of daily medication and in clinical drug efficacy trials. Most of them were simple peak flow meters, which showed only PEF (peak expiratory flow). In the 1990s, Abboud and Bruderman published articles about a transtelephonic portable personal spirometer (so-called Spirophone AG-SP) with a remote receiving centre (CG-80 10) which can measure lung function indices at a patient's home and transmit the data to a remote receiving centre for the analysis of both spirograms and flow-volume curves. After the evaluation of 15 subjects, the authors concluded that the devices were suitable only for patients who were able to perform the forced expiratory manoeuvre by themselves and could respond to advice given over the telephone. In our AioCare system, the patients have real-time information about the correctness of the maneuvers performed, which allows us to correct their assessment [40,41]. 
At that time, for patients with asthma, the Home Asthma Telemonitoring (HAT) system was evaluated by Finkelstein, in which all seventeen patients, out of 19 invited, participated in the study and were monitored for three weeks. This system aimed to help to follow their self-care plans according to the NAEPP recommendations; however only $29.5 \%$ of patients independently reviewed their results at least once a week at home [17]. Moreover, in asthmatic children, portable spirometers were used, but initially only in clinical trials [42].

Gradually, spirometry was increasingly used for the assessment of lung function in children-not only in relation to asthma but also for other diseases such as cystic fibrosis (CF) and primary ciliary dyskinesia (PCD), and not only for clinical trials but also for daily monitoring of lung function $[18,43]$.

Currently, about 16 devices for the monitoring of basic lung function parameters exist; however, only $31 \%$ provided in-app videos on how to perform the breathing manoeuvres. Only $44 \%$ of them give immediate feedback on the quality of the breathing manoeuvre. Information on the data security (63\%), measurement accuracy $(50 \%)$, and association with patient outcomes $(0 \%)$ was commonly limited. Thus, the benefit from the portable electronic spirometers in asthma patients may be limited due to the lack of patient outcome data [44].

In our study, we found that all participants reported the benefits of home telemonitoring, and most of them pointed to an improvement in breathing as the most important benefit achieved. We tried to objectify these results through careful analysis of the difference in the spirometry between the first inclusive visit and the last one. In control hospital assessments, the study group did not achieve an improvement in the value of the spirometry parameters. However, analyzing the results of individual patients, some of them presented an increase in FVC, which was confirmed by control hospital tests. It is possible that this effect may be related to the interdependence of muscle strength and lung function, although, in our study, the strength of the respiratory muscles (measured as MIP, MEP) did not depend on the age of the patient but affected lung capacity. The participants with stronger respiratory muscles presented better lung capacity. The muscle strength of the upper limb also positively correlated with lung capacity, which resulted in higher forced volume capacity. This was confirmed by regression analysis, where the value of handgrip strength was the most important floating factor for FVC increase during the three-month study.

It also seems that the greatest benefit from e-spirometry was reached by patients who regularly took measurements. In the group regularly performing measurements, the correctness of measurements increased. Performing regular breathing manoeuvres during the home e-spirometry resulted not only in better patients experience in spirometry assessments but also in maintaining the strength of respiratory muscles. This could potentially lead to an increase in lung function in some patients.

In the literature, patients with other chronic diseases experienced measurable benefits of telemonitoring. The systematic reviews have found that telemonitoring for heart failure management reduces mortality risk and hospital readmissions and more frequent transmission of patient data increases its effectiveness [45]. Telemonitoring in diabetic patients (e.g., Telescot, REMOTE study) showed that this method results in an improvement in the control of blood glucose (BG) level and a significant reduction in $\mathrm{HbA1c}$, with a positive impact on co-morbidities (arterial hypertension, weight, dyslipidemia) [15]. During the COVID-19 pandemic, telemonitoring has proven to be particularly useful and creating opportunities for continuity of care to patients in a complex and novel setting. During this time, in England, as many as $88 \%$ of 391 children with chronic respiratory diseases (CF, PCD, asthma) that received home telemonitoring devices felt it improved quality of care [46]. Amorim et al. found that the number of face-to-face consultations fell by $75 \%$ at the beginning of the pandemic and a portable home spirometer in patients with COPD proved to be very useful in ensuring continuity of care and the possibility of rapid therapeutic intervention in these patients [47]. 
Another interesting finding of our study was that telemonitoring seems to be most attractive to the patients in the first month of use, when regular measurements twice a day were used by over $30 \%$ of patients and single manoeuvres per day were performed by over $60 \%$ of participants. In the next two months of telemonitoring, the percentage of patients with good adherence fell to less than $20 \%$ (twice daily measurements) and $40 \%$ (single daily measurement), respectively. This form of telemonitoring is new for patients with DMD and further exploration of the method and outcomes are needed.

Limitations: The results we received should be interpreted with caution due to a small group with a wide age range and severity of the disease. All participants were only of Caucasian race. The bias was due to the fact that many factors can influence variability in pulmonary function tests, not only in patients with DMD but even in healthy subjects, which should be taken into consideration. Moreover, the normal variability overtime period of three months will also depend on the disease process being monitored.

Despite these limitations of the study, home telemonitoring of pulmonary function is an innovative method that facilitates the monitoring of the disease for both the patient and the doctor.

In our previous study, we showed that it is possible to make assessments of pulmonary function at home in patients with DMD [30]. The present study showed that lung monitoring in patients with neuromuscular diseases is not only possible but participants also benefit from using home spirometry electronic devices.

Knowledge about pulmonary functions in real-time is one of the benefits of remote everyday home e-monitoring. Some of the patients, by systematic breathing manoeuvres performed during the spirometry measurements, can experience an improvement in breathing, which in some cases was confirmed by an objective spirometry examination at the hospital.

\section{Summary}

Following the progress of patients with DMD and their lung disease is the question of how best to monitor their lung function. One of the innovative methods is the telemonitoring of lung function at home.

High compliance of the home telemonitoring and the hospital results of spirometry make this method usable for everyday use for monitoring lung function and exacerbations without having to come to the hospital, which is especially important during the COVID-19 pandemic.

The benefits of this method can be experienced by both the patients and the doctors. An improvement in breathing was the most frequently reported benefit by the study participants from the respiratory telemonitoring. Moreover, performing regular breathing manoeuvres during the home spirometry may result in improved general and physical well-being and conditioning.

It seems that the greatest benefit from e-spirometry is enjoyed by patients who regularly take measurements and have maintained the strength of respiratory muscle and handgrip strength.

Even if patients benefited from this method, the attractiveness and time spent on telemonitoring decreased over time. This may be due to the fact that the present form of telemonitoring requires activity on the part of the patient.

\section{Conclusions}

The study indicates high compliance of home telemonitoring results with examination in the hospital. Benefits from home spirometry were visible for all participants; the most important benefit was breathing improvement. Remote home spirometry is usable for everyday monitoring of the lung function in DMD patients and can also be treated as respiratory muscle training. 
Supplementary Materials: The following are available online at https: / / www.mdpi.com/article/ $10.3390 / \mathrm{jcm} 11030856 / \mathrm{s} 1$, Supplement Materials: Visualizations of the individual parameters of spirometry (FVC, FEV1, PEF).

Author Contributions: Conceptualization, E.W.; methodology, E.W. and A.S.-R.; formal analysis, E.W., A.S.-R., S.M. and M.S.; investigation, E.W. and A.S.-R.; resources, E.W., data curation, E.W. and A.S.-R.; writing-original draft preparation, E.W. and A.S.-R.; writing-review and editing, E.W., A.S.-R., S.M. and M.S.; visualization, E.W., M.S. and A.S.-R.; supervision, E.J.; project administration, E.W. All authors have read and agreed to the published version of the manuscript.

Funding: Medical University of Gdańsk, Poland; nb ST-544.

Institutional Review Board Statement: This study was conducted in accordance with the guidelines of the Declaration of Helsinki and approved by the Independent Bioethics Committee for Scientific Research at Medical University of Gdańsk: NKBBN/260/2021.

Informed Consent Statement: Written informed consent was obtained from the participants and parents of each patient.

Data Availability Statement: The data presented in this study are available on request from the corresponding author. Full data are not publicly available due to privacy restrictions.

Conflicts of Interest: E.W, A.S.-R., S.M., E.J. declare no conflict of interest, MS is employed by HealthUp.

\section{References}

1. Birnkrant, D.J.; Bushby, K.; Bann, C.M.; Apkon, S.D.; Blackwell, A.; Brumbaugh, D.; Case, L.E.; Clemens, P.R.; Hadjiyannakis, S.; Pandya, S. Diagnosis and management of Duchenne muscular dystrophy, part 1: Diagnosis, and neuromuscular, rehabilitation, endocrine, and gastrointestinal and nutritional management. Lancet Neurol. 2018, 17, 251-267. [CrossRef]

2. Birnkrant, D.J.; Bushby, K.; Bann, C.M.; Alman, B.A.; Apkon, S.D.; Blackwell, A.; Case, L.E.; Cripe, L.; Hadjiyannakis, S.; Olson, A.K.; et al. Diagnosis and management of Duchenne muscular dystrophy, part 2: Respiratory, cardiac, bone health, and orthopaedic management. Lancet Neurol. 2018, 17, 347-361. [CrossRef]

3. Gayraud, J.; Ramonatxo, M.; Rivier, F.; Humberclaude, V.; Petrof, B.; Matecki, S. Ventilatory parameters and maximal respiratory pressure changes with age in Duchenne muscular dystrophy patients. Pediatr. Pulmonol. 2010, 45, 552-559. [CrossRef]

4. Balaban, B.; Matthews, D.J.; Clayton, G.H.; Carry, T. Corticosteroid treatment and functional improvement in Duchenne muscular dystrophy: Long-term effect. Am. J. Phys. Med. Rehabil. 2005, 84, 843-850. [CrossRef] [PubMed]

5. Biggar, W.D.; Harris, V.A.; Eliasoph, L.; Alman, B. Long-Term benefits of deflazacort treatment for boys with Duchenne muscular dystrophy in their second decade. Neuromuscul. Disord. 2006, 16, 249-255. [CrossRef]

6. LoMauro, A.; Romei, M.; Gandossini, S.; Pascuzzo, R.; Vantini, S.; D’Angetlo, M.G.; Aliverti, A. Evolution of respiratory function in Duchenne muscular dystrophy from childhood to adulthood. Eur. Respir. J. 2018, 51, 1701418. [CrossRef]

7. Wasilewska, E.; Małgorzewicz, S.; Meyer-Szary, J.; Sledzinska, K.; Niedoszytko, M.B.; Jalssem, E.; Wierzba, J. Pulmonary dysfunction in children with Duchenne muscular dystrophy may appear earlier than we thought-Analysis using novel methodology based on z-scores. Arch. Med. Sci. 2021. [CrossRef]

8. Kato, N.P.; Johansson, P.; Okada, I.; De Vries, A.; Kinugawa, K.; Strömberg, A.; Jaarsma, T.; Hanley, J.; Rodina-Theocharaki, A. Heart Failure Telemonitoring in Japan and Sweden: A Cross-Sectional Survey. J. Med. Internet Res. 2015, 17, e258. [CrossRef]

9. Vuorinen, A.-L.; Leppänen, J.; Kaijanranta, H.; Kulju, M.; Heliö, T.; Van Gils, M.; Lähteenmäki, J. Use of home telemonitoring to support multidisciplinary care of heart failure patients in Finland: Randomized controlled trial. J. Med. Internet Res. 2014, 16, e282. [CrossRef]

10. Aamodt, I.T.; Lycholip, E.; Celutkiene, J.; Strömberg, A.; Atar, D.; Falk, R.S.; Von Lueder, T.; Hellesø, R.; Jaarsma, T.; Lie, I. Health Care Professionals' Perceptions of Home Telemonitoring in Heart Failure Care: Cross-Sectional Survey. J. Med. Internet Res. 2019, 21, e10362. [CrossRef]

11. Seto, E.; Leonard, K.J.; Cafazzo, J.A.; Barnsley, J.; Masino, C.; Ross, H.J. Mobile phone-based telemonitoring for heart failure management: A randomized controlled trial. J. Med. Internet Res. 2012, 14, e31. [CrossRef]

12. Andrès, E.; Meyer, L.; Zulfiqar, A.-A.; Hajjam, M.; Talha, S.; Bahougne, T.; Ervé, S.; Hajjam, J.; Doucet, J.; Jeandidier, N.; et al. Telemonitoring in diabetes: Evolution of concepts and technologies, with a focus on results of the more recent studies. J. Med. Life. 2019, 12, 203-214. [CrossRef]

13. Chaudhry, S.I.; Mattera, J.A.; Curtis, J.P.; Spertus, J.A.; Herrin, J.; Lin, Z.; Phillips, C.O.; Hodshon, B.V.; Cooper, L.S.; Krumholz, H.M. Telemonitoring in patients with heart failure. N. Engl. J. Med. 2010, 363, 2301-2309. [CrossRef] [PubMed]

14. Koehler, F.; Winkler, S.; Schieber, M.; Sechtem, U.; Stangl, K.; Böhm, M.; Boll, H.; Baumann, G.; Honold, M.; Koehler, K.; et al. Impact of remote telemedical management on mortality and hospitalizations in ambulatory patients with chronic heart failure: The telemedical interventional monitoring in heart failure study. Circulation. 2011, 123, 1873-1880. [CrossRef] [PubMed] 
15. Wild, S.H.; Hanley, J.; Lewis, S.C.; McKnight, J.A.; McCloughan, L.B.; Padfield, P.L.; Parker, R.A.; Paterson, M.; Pinnock, H.; Sheikh, A.; et al. Supported Telemonitoring and Glycemic Control in People with Type 2 Diabetes: The Telescot Diabetes Pragmatic Multicenter Randomized Controlled Trial. PLoS Med. 2016, 13, e1002098. [CrossRef]

16. Nicolucci, A.; Cercone, S.; Chiriatti, A.; Muscas, F.; Gensini, G. A Randomized Trial on Home Telemonitoring for the Management of Metabolic and Cardiovascular Risk in Patients with Type 2 Diabetes. Diabetes Technol. Ther. 2015, 17, 563-570. [CrossRef] [PubMed]

17. Finkelstein, J.; O'Connor, G.; Friedmann, R.H. Development and implementation of the home asthma telemonitoring (HAT) system to facilitate asthma self-care. Stud. Health Technol. Inform. 2001, 84, 810-814.

18. Shakkottai, A.; Kaciroti, N.; Kasmikha, L.; Nasr, S.Z. Impact of home spirometry on medication adherence among adolescents with cystic fibrosis. Pediatr. Pulmonol. 2018, 53, 431-436. [CrossRef]

19. Crimi, C.; Impellizzeri, P.; Campisi, R.; Nolasco, S.; Spanevello, A.; Crimi, N. Practical considerations for spirometry during the COVID-19 outbreak: Literature review and insights. Pulmonology 2021, 27, 438-447. [CrossRef]

20. Crimi, C.; Impellizzeri, P.; Campisi, R.; Spicuzza, L.; Vancheri, C.; Crimi, N. Resumption of respiratory outpatient services in the COVID-19 era: Experience from Southern Italy. Am. J. Infect. Control. 2020, 48, 1087-1089. [CrossRef]

21. Trucco, F.; Domingos, J.P.; Tay, C.G.; Ridout, D.; Maresh, K.; Munot, P.; Sarkozy, A.; Robb, S.; Quinlivan, R.; Riley, M.; et al Cardiorespiratory Progression Over 5 Years and Role of Corticosteroids in Duchenne Muscular Dystrophy: A Single-Site Retrospective Longitudinal Study. Chest 2020, 158, 1606-1616. [CrossRef] [PubMed]

22. Buyse, G.M.; Voit, T.; Schara, U.; Straathof, C.S.M.; D’Angelo, M.G.; Bernert, G.; Cuisset, J.-M.; Finkel, R.S.; Goemans, N.; McDonald, C.M.; et al. Efficacy of idebenone on respiratory function in patients with Duchenne muscular dystrophy not using glucocorticoids (DELOS): A double-blind randomised placebo-controlled phase 3 trial. Lancet 2015, 385, 1748-1757. [CrossRef]

23. Buyse, G.M.; Voit, T.; Schara, U.; Straathof, C.S.; D’Angelo, M.G.; Bernert, G.; Cuisset, J.-M.; Finkel, R.S.; Goemans, N.; Rummey, C.; et al. Treatment effect of idebenone on inspiratory function in patients with Duchenne muscular dystrophy. Pediatr. Pulmonol. 2017, 52, 508-515. [CrossRef] [PubMed]

24. McDonald, C.M.; Meier, T.; Voit, T.; Schara, U.; Straathof, C.S.; D’Angelo, M.G.; Bernert, G.; Cuisset, J.-M.; Finkel, R.S.; Goemans, N.; et al. Idebenone reduces respiratory complications in patients with Duchenne muscular dystrophy. Neuromuscul. Disord. 2016, 26, 473-480. [CrossRef]

25. Finder, J.D.; Birnkrant, D.; Carl, J.; Farber, H.J.; Gozal, D.; Iannaccone, S.T.; Kovesi, T.; Kravitz, R.M.; Panitch, H.; Schramm, C.; et al. Respiratory care of the patient with duchenne muscular dystrophy: ATS consensus statement. Am. J. Respir. Crit. Care Med. 2004, 170, 456-465. [CrossRef] [PubMed]

26. Topin, N.; Matecki, S.; Le Bris, S.; Rivier, F.; Echenne, B.; Prefaut, C.; Ramonatxo, M. Dose-Dependent effect of individualized respiratory muscle training in children with Duchenne muscular dystrophy. Neuromuscul. Disord. 2002, 12, 576-583. [CrossRef]

27. Rodrigues, M.R.; Carvalho, C.R.F.; Santaella, D.F.; Lorenzi-Filho, G.; Marie, S.K.N. Effects of yoga breathing exercises on pulmonary function in patients with Duchenne muscular dystrophy: An exploratory analysis. J. Bras. Pneumol. Publicacao Soc. Bras. Pneumol. Tisilogia 2014, 40, 128-133. [CrossRef]

28. Williamson, E.; Pederson, N.; Rawson, H.; Daniel, T. The Effect of Inspiratory Muscle Training on Duchenne Muscular Dystrophy: A Meta-analysis. Pediatr. Phys. Ther. Off. Publ. Sect. Pediatr. Am. Phys. Ther. Assoc. 2019, 31, 323-330. [CrossRef]

29. Sobierajska-Rek, A.; Mański, Ł.; Jabłońska-Brudło, J.; Śledzińska, K.; Wasilewska, E.; Szalewska, D. Respiratory Telerehabilitation of Boys and Young Men with Duchenne Muscular Dystrophy in the COVID-19 Pandemic. Int. J. Environ. Res. Public Health 2021, 18, 6179. [CrossRef]

30. Wasilewska, E.; Sobierajska-Rek, A.; Małgorzewicz, S.; Soliński, M.; Szalewska, D.; Jassem, E. Is It Possible to Have Home E-Monitoring of Pulmonary Function in Our Patients with Duchenne Muscular Dystrophy in the COVID-19 Pandemic?-A One Center Pilot Study. Int. J. Environ. Res. Public Health 2021, 18, 8967. [CrossRef]

31. Aiocare. Available online: https://healthcloud.aiocare.com (accessed on 1 December 2021).

32. Rochester, C.L.; Vogiatzis, I.; Holland, A.E.; Lareau, S.C.; Marciniuk, D.D.; Puhan, M.; Spruit, M.A.; Masefield, S.C.; Casaburi, R.; Clini, E.; et al. An Official American Thoracic Society/European Respiratory Society Policy Statement: Enhancing Implementation, Use, and Delivery of Pulmonary Rehabilitation. Am. J. Respir Crit. Care Med. 2015, 192, 1373-1386. [CrossRef] [PubMed]

33. Graham, B.L.; Steenbruggen, I.; Miller, M.R.; Barjaktarevic, I.Z.; Cooper, B.G.; Hall, G.L.; Hallstrand, T.S.; Kaminsky, D.A.; McCarthy, K.; McCormack, M.C.; et al. Standardization of Spirometry 2019 Update. An Official American Thoracic Society and European Respiratory Society Technical Statement. Am. J. Respir. Crit. Care Med. 2019, 200, e70-e88. [CrossRef] [PubMed]

34. Mayer, O.H.; Aliverti, A.; Meier, T. Breathe Duchenne: What natural history studies tell us about the progression of pulmonary morbidity in Duchenne muscular dystrophy. Neuromuscul. Disord. 2018, 28, 910-913. [CrossRef]

35. Vignos, P.J.J.; Spencer, G.E.J.; Archibald, K.C. Management of progressive muscular dystrophy in childhood. JAMA 1963, 184, 89-96. [CrossRef]

36. Brooke, M.H.; Griggs, R.C.; Mendell, J.R.; Fenichel, G.M.; Shumate, J.B.; Pellegrino, R.J. Clinical trial in Duchenne dystrophy. I. The design of the protocol. Muscle Nerve 1981, 4, 186-197. [CrossRef]

37. Mayhew, A.G.; Coratti, G.; Mazzone, E.S.; Klingels, K.; James, M.; Pane, M.; Straub, V.; Goemans, N.; Mercuri, E.; Ricotti, V.; et al. Performance of Upper Limb module for Duchenne muscular dystrophy. Dev. Med. Child. Neurol. 2020, 62, 633-639. [CrossRef] [PubMed] 
38. Eaton, T.; Withy, S.; Garrett, J.E.; Mercer, J.; Whitlock, R.M.; Rea, H.H. Spirometry in primary care practice: The importance of quality assurance and the impact of spirometry workshops. Chest 1999, 116, 416-423. [CrossRef]

39. Kupczyk, M.; Hofman, A.; Kołtowski, Ł.; Kuna, P.; Łukaszyk, M.; Buczyłko, K.; Bodzenta-Łukaszyk, A.; Nastałek, P.; Soliński, M.; Dąbrowiecki, P. Home self-monitoring in patients with asthma using a mobile spirometry system. J. Asthma 2021, 58, 505-511. [CrossRef]

40. Abboud, S.; Bruderman, I. Assessment of a new transtelephonic portable spirometer. Thorax 1996, 51, 407-410. [CrossRef]

41. Bruderman, I.; Abboud, S. Telespirometry: Novel system for home monitoring of asthmatic patients. Telemed. J. 1997, 3, 127-133. [CrossRef]

42. Mortimer, K.M.; Fallot, A.; Balmes, J.R.; Tager, I.B. Evaluating the use of a portable spirometer in a study of pediatric asthma. Chest 2003, 123, 1899-1907. [CrossRef] [PubMed]

43. Logie, K.; Welsh, L.; Ranganathan, S.C. Telehealth spirometry for children with cystic fibrosis. Arch. Dis. Child. 2020, 105, 1203-1205. [CrossRef] [PubMed]

44. Carpenter, D.M.; Jurdi, R.; Roberts, C.A.; Hernandez, M.; Horne, R.; Chan, A. A Review of Portable Electronic Spirometers: Implications for Asthma Self-Management. Curr. Allergy Asthma Rep. 2018, 18, 53. [CrossRef] [PubMed]

45. Bashi, N.; Karunanithi, M.; Fatehi, F.; Ding, H.; Walters, D. Remote Monitoring of Patients with Heart Failure: An Overview of Systematic Reviews. J. Med. Internet Res. 2017, 19, e18. [CrossRef]

46. Richardson, C.H.; Orr, N.J.; Ollosson, S.L.; Irving, S.J.; Balfour-Lynn, I.M.; Carr, S.B. Initiating home spirometry for children during the COVID-19 pandemic-A practical guide. Paediatr. Respir. Rev. 2021. [CrossRef]

47. Kirkby, J.; Bountziouka, V.; Lum, S.; Wade, A.; Stocks, J. Natural variability of lung function in young healthy school children. Eur. Respir. J. 2016, 48, 411-419. [CrossRef] 